\title{
Stability of singular time-delay systems in the sense of non-Lyapunov: Classical and modern approach
}

\author{
Dragutin Lj. Debeljković ${ }^{1}$, Sreten B. Stojanović ${ }^{2}$, Marko S. Aleksendrić ${ }^{1}$ \\ ${ }^{1}$ University of Belgrade, Faculty of Mechanical Engineering, Department of Control Engineering, Belgrade, Serbia \\ ${ }^{2}$ University of Niš, Faculty of Technology, Leskovac, Serbia
}

\begin{abstract}
This paper provides sufficient conditions for both practical stability and finite-time stability of linear singular continuous time-delay systems, which can be mathematically described as $E \dot{\mathbf{x}}(t)=A_{0} \mathbf{x}(t)+A_{1} \mathbf{x}(t-\tau)$. Considering a finite-time stability concept, new delay independent and delay dependent conditions have been derived using the approach based on the Lyapunov-like functions and their properties on the subspace of consistent initial conditions. These functions do not need to have the properties of positivity in the whole state space and negative derivatives along the system trajectories. When the practical stability has been analyzed, the above mentioned approach was combined and supported by the classical Lyapunov technique to guarantee the attractivity property of the system behavior. Moreover, a linear matrix inequality (LMI) approach has been applied in order to get less conservative conditions.
\end{abstract}

Keywords: singular system, time-delay, finite-time stability, attractive practical stability, linear matrix inequality.

\section{SCIENTIFIC PAPER}

UDC 51:517.5

Hem. Ind. 67 (2) 193-202 (2013)

doi: 10.2298/HEMIND120403061D

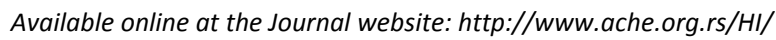

Dynamic physical processes arise in many areas of engineering, science and economics, and are usually modelled using ordinary differential equations (ODEs) or partial differential equations (PDEs). However, some of the states in these physical processes are constrained, and such states are governed by algebraic equations and the resulting mathematical model contains ODEs/PDEs coupled with nonlinear algebraic equations. During the past three decades, DAE systems have attracted much attention due to the comprehensive applications in economics, as the Leontief dynamic model, in electrical applications using the theory described in [1], in mechanical models as in [2], in chemical engineering, etc. Models of chemical processes, for example, typically consist of differential equations describing the dynamic balances of mass and energy while additional algebraic equations account for thermodynamic equilibrium relations, steady state assumptions, and empirical correlations. Some particular properties of DAEs and their significance in chemical engineering are illustrated by [3-5]. Numerical solution of DAE systems is more difficult as compared to ODE models due to the existence of linear and non-linear algebraic equations and due to discontinuities in the algebraic variables over the independent variable space. Systems described by DAEs are referred to as

Correspondence: D.Lj. Debeljković, University of Belgrade, Faculty of Mechanical Engineering, Department of Control Engineering, 11000 Belgrade, Serbia.

E-mail: ddebeljkovic@mas.bg.ac.rs

Paper received: 3 April, 2012

Paper accepted: 5 June, 2012 degenerate, descriptor, generalized, semi-state systems or singular systems.

For illustration purpose we give an example of singular system from chemical engineering. It is the separation of two alcohols (methanol, $n$-propanol) in a 40 tray distillation column with one feed stream which is described in [5]. A singular model with concentration $x_{\mathrm{B}}$ in the reboiler, position of profile $s_{r}$ in the rectifying section, concentration $x_{\mathrm{M}}$ for the feed tray, position of profile $s_{\mathrm{S}}$ in the stripping section, and concentration $x_{\mathrm{D}}$ in the condenser as descriptor variables is described by the following matrix equation [5]:

$E \dot{x}(t)=A x(t)+B_{1} u_{1}(t)+B_{2} u_{2}(t)$

where:

$E=\left[\begin{array}{lllll}\square & 0 & 0 & 0 & 0 \\ \square & \square & \square & 0 & 0 \\ 0 & 0 & \square & 0 & 0 \\ 0 & 0 & \square & \square & \square \\ 0 & 0 & 0 & 0 & \square\end{array}\right], \quad A=\left[\begin{array}{lllll}\square & \square & \square & 0 & 0 \\ \square & \square & \square & 0 & 0 \\ \square & \square & \square & \square & \square \\ 0 & 0 & \square & \square & \square \\ 0 & 0 & \square & \square & \square\end{array}\right]$,

$B_{1}=\left[\begin{array}{ll}0 & \square \\ 0 & \square \\ \square & \square \\ 0 & 0 \\ 0 & 0\end{array}\right], \quad B_{2}=\left[\begin{array}{ll}\square & \square \\ \square & \square \\ \square & \square \\ \square & \square \\ 0 & \square\end{array}\right]$ 


$$
x(t)=\left[\begin{array}{c}
\Delta x_{B} \\
\Delta s_{r} \\
\Delta x_{M} \\
\Delta s_{s} \\
\Delta x_{D}
\end{array}\right], \quad u_{1}(t)=\left[\begin{array}{c}
\Delta x_{F} \\
\Delta F
\end{array}\right], \quad u_{2}(t)=\left[\begin{array}{c}
\Delta L \\
\Delta V
\end{array}\right]
$$

Here " $\square$ " denotes numerical entries and $\Delta z=z(t)-$ $-z_{n}$ difference of a current value of a variable $z(t)$ and its nominal value, $z_{n}$. The mixture is fed in the column with the feed flow rate, $F$. Feed flow rate, $F$, and feed composition, $x_{F}$ (molar fraction), are determined by upstream processes. The liquid flow rate, $L$, and vapor flow rate, $V$, are considered to be control inputs.

It has been observed that a variety of singular systems are characterized by the phenomena of time delay. Such systems are called singular systems with time delay. Time delay can appear in the input variables, output variables and/or the state space vector. In general, the dynamic behavior of continuous-time singular systems with delays is more complicated than that of system without any time-delay because the continuous time-delay system is infinite dimensional. For this reason, over the past decades, there has been increasing interest in the stability analysis for singular time-delay systems and many results have been reported in the literature [6-11].

In practice one is not only interested in the system stability (e.g., in the sense of Lyapunov approach), but also in the bounds of system trajectories. A system could be stable but completely useless because it possesses undesirable transient performances. Thus, it may be useful to consider the stability of such systems with respect to certain sub-sets of state-space, which are a priori defined for a given problem. Besides that, it is of particular significance to consider the behavior of dynamical systems only over a finite time interval. These bound properties of system responses, i.e. solutions of system models, are important from the engineering point of view. Realizing this fact, numerous definitions of the so-called technical and practical stability, as well as finite-time stability have been introduced.

A system is said to be finite-time stable (FTS) if, once a time interval is fixed, its state does not exceed some bounds during this time interval. Little work has been done for the finite-time stability and stabilization of singular time-delay systems. Some results on FTS and practical stability can be found in [12-22] (singular systems) and [23-24] (singular time-delay systems). However, according to the author's knowledge, there is no result available yet on finite-time stability and attractive practical stability for a class of linear timedelay systems using linear matrix inequality.

In this article, we consider the problem of finitetime and practical stability for a class of linear singular time-delay systems. First, we present delay-independent and delay-dependent criteria which provide sufficient conditions for a singular time-delay system to be regular, impulse free and finite-time stable. Then, using the linear matrix inequality (LMI) approach, novel sufficient conditions for the finite-time and attractive practical stability are derived. Numerical examples are given to show the effectiveness of the proposed approaches.

\section{NOTATION AND PRELIMINARIES}

The following notations will be used throughout the paper. $\mathfrak{R}^{n}$ denotes the $n$-dimensional Euclidean space, $C^{n}$ complex vector space and $\mathfrak{R}^{n \times m}$ is the set of all real matrices of dimension $n \times m$. Superscript " $\mathrm{T}$ " stands for matrix transposition. $X>0$ means that $X$ is real symmetric and positive definite and $X>Y$ means that the matrix $X-Y$ is positive definite. In symmetric block matrices or long matrix expressions, we use an asterisk $\left({ }^{*}\right)$ to represent a term that is induced by symmetry. I stands for identity matrix, $\boldsymbol{W}(\mathbf{X})$ null space (kernel) of matrix $\mathbf{X}$ and $\lambda(\mathbf{X})$ eigenvalue of matrix $\mathbf{X}$. Matrices, if their dimensions are not explicitly stated, are assumed to be compatible for algebraic operations.

Consider a linear continuous singular system with state delay, described by:

$E \dot{\mathbf{x}}(t)=A_{0} \mathbf{x}(t)+A_{1} \mathbf{x}(t-\tau)$

with a known compatible vector valued function of the initial conditions:

$\mathbf{x}(t)=\boldsymbol{\phi}(t),-\tau \leq t \leq 0$

where $x(t) \in \mathfrak{R}^{n}$ is the state vector, $u(t) \in \mathfrak{R}^{m}$ is the control input, $\tau$ is constant time delay, $A_{0} \in \mathfrak{R}^{n \times n}$, $A_{1} \in \mathfrak{R}^{n \times n}$ and $B \in \mathfrak{R}^{n \times m}$ are known constant matrices. The matrix $E \in \mathfrak{R}^{n \times n}$ may be singular, and it is assumed that $\operatorname{rank}(\hat{E})=r \leq n$.

The following definition will be used in the proof of the main results.

Definition 1. Matrix pair $\left(\mathbf{E}, \mathbf{A}_{0}\right)$ is said to be regular if $\operatorname{det}\left(s \mathbf{E}-\mathbf{A}_{0}\right)$ is not identically zero [6].

Definition 2. The matrix pair $\left(\mathbf{E}, \mathbf{A}_{0}\right)$ is said to be impulse-free if $\operatorname{deg} \operatorname{det}\left(s \mathbf{E}-\mathbf{A}_{0}\right)=\operatorname{rankE}[6]$.

The linear continuous singular time delay system (2) may have an impulsive solution. However, the regularity and the absence of impulses of the matrix pair $\left(\mathbf{E}, \mathbf{A}_{0}\right)$ ensure the existence and uniqueness of an impulse-free solution of the system. The existence of the solutions is defined in the following Lemma.

Lemma 1. Suppose that the matrix pair $\left(\mathbf{E}, \mathbf{A}_{0}\right)$ is regular and impulsive free, then the solution to (2) exists and is impulse-free and unique on $[0, \infty)[6]$.

Lemma 2. Continuous singular system:

$E \dot{x}(t)=A x(t)$ 
where:

$$
E=\left[\begin{array}{cc}
I_{r} & 0 \\
0 & 0
\end{array}\right], \quad A=\left[\begin{array}{ll}
A_{11} & A_{12} \\
A_{21} & A_{22}
\end{array}\right]
$$

is regular and impulse-free if and only if $A_{22}$ is invertible [12].

In view of this, we introduce the following definition for singular time-delay system (2).

Definition 3. The singular continuous system with state delay (2) is said to be regular and impulse-free, if the matrix pair $\left(\mathbf{E}, \mathbf{A}_{0}\right)$ is regular and impulse-free [6].

Remark 1 . The singularity of matrix $\mathbf{E}$ will ensure that solutions of (2) exist only for special choices of $\boldsymbol{\phi}(t) \in \mathcal{W}_{\text {cont. }}^{*}, \forall t \in[-\tau, 0]$. In the literature [25], the subspace of $\mathcal{W}_{k}^{*}$ of consistent initial conditions is shown to be the limit of the nested subspace algorithm:

$$
\begin{gathered}
W_{k, 0}^{*}=\mathfrak{R}^{n} \\
\vdots \\
W_{k,(j+1)}^{*}=A_{0}^{-1}\left(E W_{k, j j}^{*}\right)_{A_{1}=0}, j \geq 0
\end{gathered}
$$

Moreover, if $\boldsymbol{\phi}(t) \in \mathcal{W}_{\mathrm{k}}^{*}, \quad \forall t \in[-\tau, 0]$ then $\mathbf{x}(t) \in \mathcal{W}_{k}^{*}, \forall t \geq 0$ and $\left(\lambda E-A_{0}\right)_{A_{1}=0}$ is invertible for some $\lambda \in \mathrm{C}$ (condition for uniqueness), then $\mathcal{W}_{k}^{*} \cap \aleph(E)=\{0\}$.

\section{MAIN RESULTS}

\section{Classical approach}

In the further analysis the following case has been considered: the subspace of consistent initial conditions for singular time delay and singular non-delay systems coincides.

As a basis for the further solution development a stability definition and theorem have been presented at this point.

Definition 4. Singular time delayed system (2) is finite-time stable with respect to $\{\alpha, \beta, T\}, \alpha<\beta$, if:

$$
\sup _{t \in[-\tau, 0]} \boldsymbol{\phi}^{T}(t) E^{T} E \boldsymbol{\phi}(t) \leq \alpha
$$

implies:

$$
\mathbf{x}^{T}(t) E^{T} E \mathbf{x}(t)<\beta, \forall t \in[0, T]
$$

Theorem 1. Consider a singular time delayed system (2) with:

$$
\begin{aligned}
& \boldsymbol{\phi}(t) \in \mathcal{W}_{\text {cont. }}^{*}, \forall t \in[-\tau, 0] \\
& \mathbf{x}^{T}(t-\theta) \mathbf{x}(t-\theta)<q \mathbf{x}^{T}(t) \mathbf{x}(t), \\
& q>0, \quad \theta \in[-\tau, 0], \quad \forall t \in[0, T]
\end{aligned}
$$

where $\mathcal{W}_{k}^{*}$ is a subspace of consistent initial conditions.

a) If there exists a positive real number $\wp$ such that:

$$
\Xi=A_{0}^{T} E+E^{T} A_{0}+E^{T} A_{1} \wp^{-1} A_{1}^{T} E+q \wp I<0
$$

then system (2) is regular, impulse free and finite-time stable with respect to $\{\alpha, \beta, T\}, \alpha<\beta$ for all $T>0$.

b) If there exists a positive real number $\wp$ such that the following conditions are satisfied:

$$
\begin{aligned}
& \Xi=A_{0}^{T} E+E^{T} A_{0}+E^{T} A_{1} \wp^{-1} A_{1}^{T} E+q \wp l>0 \\
& e^{\lambda_{\min }\left(\Xi, E^{T} E\right) T}<\frac{\beta}{\alpha}
\end{aligned}
$$

where

$$
\begin{aligned}
& \lambda_{\min }\left(\Xi, E^{T} E\right)=\min \left(\frac{\mathbf{x}^{T}(t) \Xi \mathbf{x}(t)}{\mathbf{x}^{T}(t) E^{T} E \mathbf{x}(t)}\right)= \\
& \min \left[\mathbf{x}^{T}(t) \Xi \mathbf{x}(t): \mathbf{x}^{T}(t) E^{T} E \mathbf{x}(t)=1\right]
\end{aligned}
$$

then system (2) is regular, impulse free and finitetime stable with respect to $\{\alpha, \beta, T\}, \alpha<\beta$.

Proof. The condition (9) provides that the system (2) is regular and impulse free. Next, we show the stability. Let us consider the following Lyapunov-like function:

$$
V(\mathbf{x}(t))=\mathbf{x}^{T}(t) E^{T} E \mathbf{x}(t)
$$

Total derivative $\dot{V}(t, \mathbf{x}(t))$ along the trajectories of the system is:

$$
\begin{aligned}
& \dot{V}(\mathbf{x}(t))=\dot{\mathbf{x}}^{T}(t) E^{T} E \mathbf{x}(t)+\mathbf{x}^{T}(t) E^{T} E \dot{\mathbf{x}}(t)= \\
& =\mathbf{x}^{T}(t)\left(A_{0}^{T} E+E^{T} A_{0}\right) \mathbf{x}(t)+2 \mathbf{x}^{T}(t) E^{T} A_{1} \mathbf{x}(t-\tau)
\end{aligned}
$$

Based on the known inequality:

$$
2 \mathbf{u}^{T}(t) \mathbf{v}(t-\tau) \leq \mathbf{u}^{T}(t) \Gamma^{-1} \mathbf{u}(t)+\mathbf{v}^{T}(t-\tau) \Gamma \mathbf{v}(t-\tau),
$$

$\Gamma=\Gamma^{T}>0$

we have:

$$
\begin{aligned}
& 2 \mathbf{x}^{T}(t) E^{T} A_{1} \mathbf{x}(t-\tau) \leq \mathbf{x}^{T}(t) E^{T} A_{1} \wp^{-1} A_{1}^{T} E \mathbf{x}(t)+ \\
& +\mathbf{x}^{T}(t-\tau) \wp \mathbf{x}(t-\tau)
\end{aligned}
$$

so

$$
\begin{aligned}
& \dot{V}(\mathbf{x}(t)) \leq \mathbf{x}^{T}(t)\left(A_{0}^{T} E+E^{T} A_{0}\right) \mathbf{x}(t)+ \\
& +\mathbf{x}^{T}(t) E^{T} A_{1} \wp^{-1} A_{1}^{T} E \mathbf{x}(t)+\mathbf{x}^{T}(t-\tau) \wp \mathbf{x}(t-\tau)
\end{aligned}
$$
to:

Using (10) and (12), it is clear that (18) is reduced 
$\dot{V}(\mathbf{x}(t))<\mathbf{x}^{T}(t)\left(A_{0}^{T} E+E^{T} A_{0}\right) \mathbf{x}(t)+$

$\mathbf{x}^{T}(t) E^{T} A_{1} \wp^{-1} A_{1}^{T} E \mathbf{x}(t)+q \wp \times \mathbf{x}^{T}(t) x(t)=$

$=\mathbf{x}^{T}(t)\left(A_{0}^{T} E+E^{T} A_{0}+E^{T} A_{1} \wp^{-1} A_{1}^{T} E+q \wp ।\right) \times$

$\times \mathbf{x}(t)=\mathbf{x}^{T}(t) \Xi \mathbf{x}(t)$

$\Xi=A_{0}^{T} E+E^{T} A_{0}+E^{T} A_{1} \wp^{-1} A_{1}^{T} E+q \wp ।$

If condition (11) is satisfied, then system (2) is asymptotically stable in the sense in Lyapunov. In this case, the finite time stability is guaranteed for all $T>0$.

From (19) we have:

$$
\frac{\mathrm{d}\left[\mathbf{x}^{T}(t) E^{T} E \mathbf{x}(t)\right]}{\mathbf{x}^{T}(t) E^{T} E \mathbf{x}(t)}<\frac{\mathbf{x}^{T}(t) \Xi \mathbf{x}(t)}{\mathbf{x}^{T}(t) E^{T} E \mathbf{x}(t)} \mathrm{d} t
$$

Inequality (20) is satisfied if the following condition is valid:

$$
\begin{aligned}
& \frac{\mathrm{d}\left[\mathbf{x}^{T}(t) E^{T} E \mathbf{x}(t)\right]}{\mathbf{x}^{T}(t) E^{T} E \mathbf{x}(t)} \leq \min \left(\frac{\mathbf{x}^{T}(t) \Xi \mathbf{x}(t)}{\mathbf{x}^{T}(t) E^{T} E \mathbf{x}(t)}\right) \mathrm{d} t= \\
& \lambda_{\min }\left(\Xi, E^{T} E\right) \mathrm{d} t \\
& \lambda_{\min }\left(\Xi, E^{T} E\right)= \\
& =\min \left[\mathbf{x}^{T}(t) \Xi \mathbf{x}(t): \mathbf{x}^{T}(t) E^{T} E \mathbf{x}(t)=1\right]
\end{aligned}
$$

After integrating the previous inequality, we get:

$\mathbf{x}^{T}(t) E^{T} E x(t)<\mathbf{x}^{T}(0) E^{T} E x(0) e^{\lambda_{\min }\left(\Xi, E^{T} E\right) t}$

Finally, if the first condition of Definition 4 is used, then:

$$
\mathbf{x}^{T}(t) E^{T} E \mathbf{x}(t)<\alpha e^{\lambda_{\min }\left(\Xi, E^{T} E\right) t}
$$

Conditions (12), (13) and inequality (23) imply:

$$
\mathbf{x}^{T}(t) E^{T} E \mathbf{x}(t)<\beta, \quad \forall t \in[0, T]
$$

This completes the proof.

Lemma 3. For any real constant $\wp>0$ and any symmetric, positive definite matrix $\Xi=\Xi^{T}>0$ the following condition is satisfied:

$$
\begin{aligned}
& -2 \mathbf{u}^{T}(t) \mathbf{v}(t) \leq \wp \mathbf{u}^{T}(t) \Xi^{-1} \mathbf{u}(t)+ \\
& +\wp{ }^{-1} \mathbf{v}^{T}(t) \Xi \mathbf{v}(t)
\end{aligned}
$$

Theorem 2. Consider a singular time delayed system (2) with:

$$
\begin{aligned}
& \boldsymbol{\phi}(t) \in \mathcal{W}_{\text {cont. }}^{*}, \quad \forall t \in[-\tau, 0] \\
& \mathbf{x}^{T}(t-\theta) \mathbf{x}(t-\theta)<q \mathbf{x}^{T}(t) E^{T} E \mathbf{x}(t), \\
& q>0, \quad \theta \in[-2 \tau, 0], \quad \forall t \in[0, T]
\end{aligned}
$$

where $\mathcal{W}_{\mathrm{k}}^{*}$ is a subspace of consistent initial conditions.

a) If there exists a positive real number $\wp$ such that:

$$
\begin{aligned}
& \Pi=\left(A_{0}+A_{1}\right)^{T} E+E^{T}\left(A_{0}+A_{1}\right)+ \\
& +\tau \wp A_{1}\left(A_{0} A_{0}^{T}+A_{1} A_{1}^{T}\right) A_{1}^{T}+ \\
& +2 q \tau \wp^{-1} l<0
\end{aligned}
$$

then system (2) is regular, impulse free and finite-time stable with respect to $\{\alpha, \beta, T\}, \alpha<\beta$ for all $T>0$.

b) If there exists a positive real number $\wp$ such that the following conditions are satisfied:

$$
\begin{aligned}
& \Pi=\left(A_{0}+A_{1}\right)^{T} E+E^{T}\left(A_{0}+A_{1}\right)+ \\
& +\tau \wp A_{1}\left(A_{0} A_{0}^{T}+A_{1} A_{1}^{T}\right) A_{1}^{T}+ \\
& +2 q \tau \wp \wp^{-1} l>0 \\
& e^{\lambda_{\min }(\Pi) T}<\frac{\beta}{\alpha}
\end{aligned}
$$

where:

$$
\begin{aligned}
& \lambda_{\min }\left(\Pi, E^{T} E\right)=\min \left(\frac{\mathbf{x}^{T}(t) \Pi \mathbf{x}(t)}{\mathbf{x}^{T}(t) E^{T} E \mathbf{x}(t)}\right)= \\
& =\min \left[\mathbf{x}^{T}(t) \Pi \mathbf{x}(t): \mathbf{x}^{T}(t) E^{T} E \mathbf{x}(t)=1\right]
\end{aligned}
$$

then system (2) is regular, impulse free and finite-time stable with respect to $\{\alpha, \beta, T\}, \alpha<\beta$.

Proof. The condition (9) provides that the system (2) is regular and impulse free.

Next, we show the stability.

It is very well known that if the $x(t)$ is continuously differentiable for $t \geq 0$, one can write:

$$
\mathbf{x}(t-\tau)=\mathbf{x}(t)-\int_{t-\tau}^{t}\left(A_{0} \mathbf{x}(s)+A_{1} \mathbf{x}(s-\tau)\right) \mathrm{d} s
$$

for $t \geq \tau$ [14], so basic system's dynamics in (2) can be rewritten as:

$$
\begin{aligned}
& E \dot{\mathbf{x}}(t)=\left(A_{0}+A_{1}\right) \mathbf{x}(t)- \\
& -A_{1} \int_{t-\tau}^{t}\left(A_{0} \mathbf{x}(s)+A_{1} \mathbf{x}(s-\tau)\right) \mathrm{d} s
\end{aligned}
$$

for arbitrary continuous initial function $\varphi(t)$ on time interval $t \in[-2 \tau, 0]$.

It is declared in [26] that asymptotic stability of (33) can assure the asymptotic stability of original system (2), since the basic system (2) is only a special case of system, whose dynamics is described by (33). 

tion:

Let us consider the following Lyapunov-like func-

$$
V(\mathbf{x}(t))=\mathbf{x}^{T}(t) E^{T} E \mathbf{x}(t)
$$

The total derivative $\dot{V}(\mathbf{x}(t))$ along the trajectories of the system (33) yields:

$$
\begin{aligned}
& \dot{V}(\mathbf{x}(t))=\mathbf{x}^{T}(t)\left(\left(A_{0}+A_{1}\right)^{T} E+\right. \\
& \left.E^{T}\left(A_{0}+A_{1}\right)\right) \mathbf{x}(t)- \\
& -2 \int_{t-\tau}^{t} \mathbf{x}^{T}(t) E^{T} A_{1}\left(A_{0} \mathbf{x}(s)+A_{1} \mathbf{x}(s-\tau)\right) \mathrm{d} s
\end{aligned}
$$

Furthermore, by using Lemma 3 and (27) we have:

$$
\begin{aligned}
& -2 \int_{t-\tau}^{t} \mathbf{x}^{T}(t) E^{T} A_{1} A_{0} \mathbf{x}(s) \mathrm{d} s \leq \\
& \leq \int_{t-\tau}^{t} \wp \mathbf{x}^{T}(t) E^{T} A_{1} A_{0} A_{0}^{T} A_{1}^{T} E \mathbf{x}(t) \mathrm{d} s+ \\
& +\int_{t-\tau}^{t} \wp^{-1} \mathbf{x}^{T}(s) \mathbf{x}(s) \mathrm{d} s< \\
& <\tau \wp \mathbf{x}^{T}(t) E^{T} A_{1} A_{0} A_{0}^{T} A_{1}^{T} E \mathbf{x}(t)+ \\
& +\int_{t-\tau}^{t} q \wp^{-1} \mathbf{x}^{T}(t) E^{T} E \mathbf{x}(t) \mathrm{d} s \\
& <\mathbf{x}^{T}(t) E^{T}\left(\tau \wp A_{1} A_{0} A_{0}^{T} A_{1}^{T}+q \tau \wp^{-1} I\right) E \mathbf{x}(t) \\
& -2 \int_{-\tau}^{0} \mathbf{x}^{T}(t) E^{T} A_{1} A_{1} \mathbf{x}(s-\tau) \mathrm{d} s< \\
& <\int_{t-\tau}^{t} \wp \mathbf{x}^{T}(t) E^{T} A_{1} A_{1} A_{1}^{T} A_{1}^{T} E \mathbf{x}(t) \mathrm{d} s \\
& +\int_{t-\tau}^{t} \wp^{-1} \mathbf{x}^{T}(s-\tau) \mathbf{x}(s-\tau) \mathrm{d} s \\
& <\tau \wp \mathbf{x}^{T}(t) E^{T} A_{1} A_{1} A_{1}^{T} A_{1}^{T} E \mathbf{x}(t)+ \\
& +\int_{t-\tau}^{t} q \wp^{-1} \mathbf{x}^{T}(t) E^{T} E \mathbf{x}(t) \mathrm{d} s \\
& <\mathbf{x}^{T}(t) E^{T}\left(\tau \wp A_{1} A_{1} A_{1}^{T} A_{1}^{T}+q \tau \wp^{-1} I\right) E \mathbf{x}(t)
\end{aligned}
$$

Using (35), (36) and (37) we get:

$$
\begin{aligned}
& \dot{V}(\mathbf{x}(t))<\mathbf{x}^{T}(t) \Pi \mathbf{x}(t) \\
& \Pi=\left(A_{0}+A_{1}\right)^{T} E+E^{T}\left(A_{0}+A_{1}\right)+ \\
& \tau \wp A_{1}\left(A_{0} A_{0}^{T}+A_{1} A_{1}^{T}\right) A_{1}^{T}+2 q \tau \wp^{-1} I
\end{aligned}
$$

If condition (28) is satisfied, then system (2) is asymptotically stable in the sense in Lyapunov. In this case, the finite time stability is guaranteed for all $T>0$.

From (38) one can get:

$\frac{\mathrm{d}\left[\mathbf{x}^{T}(t) E^{T} E \mathbf{x}(t)\right]}{\mathbf{x}^{T}(t) E^{T} E \mathbf{x}(t)}<\frac{\mathbf{x}^{T}(t) \Pi \mathbf{x}(t)}{\mathbf{x}^{T}(t) E^{T} E \mathbf{x}(t)} \mathrm{d} t$

If

$$
\begin{aligned}
& \frac{d\left[\mathbf{x}^{T}(t) E^{T} E \mathbf{x}(t)\right]}{\mathbf{x}^{T}(t) E^{T} E \mathbf{x}(t)} \leq \min \left(\frac{\mathbf{x}^{T}(t) \Pi \mathbf{x}(t)}{\mathbf{x}^{T}(t) E^{T} E \mathbf{x}(t)}\right) \mathrm{d} t= \\
& =\lambda_{\min }\left(\Pi, E^{T} E\right) \mathrm{d} t \\
& \lambda_{\min }\left(\Pi, E^{T} E\right)= \\
& =\min \left[\mathbf{x}^{T}(t) \Pi \mathbf{x}(t): \mathbf{x}^{T}(t) E^{T} E \mathbf{x}(t)=1\right]
\end{aligned}
$$

then Eq. (39) is satisfied. After integrating the previous inequality we get:

$$
\mathbf{x}^{T}(t) E^{T} E \mathbf{x}(t)<\mathbf{x}^{T}(0) E^{T} E \mathbf{x}(0) e^{\lambda_{\min }\left(\Pi, E^{T} E\right) t}
$$

Finally, if one use the first condition of Definition (4), for $\forall \boldsymbol{\phi}(t) \in \mathcal{W}_{k}^{*}$, we get:

$$
\mathbf{x}^{T}(t) E^{T} E \mathbf{x}(t)<\alpha e^{\lambda_{\min }\left(\Pi, E^{T} E\right) T}
$$

Conditions (29), (30) and (42) yield to:

$\mathbf{x}^{T}(t) E^{T} E \mathbf{x}(t)<\alpha \frac{\beta}{\alpha}<\beta, \quad \forall t \in[0, T]$

This completes the proof.

Remark 2. Expressions (14) and (31) are known as the Rayleigh quotient, the minimum of which can be determined using appropriate standard numerical methods.

Remark 3. Conditions (10) and (27) are main sources of the conservatism in Theorem 1 and 2. Namely, it is difficult to determine the parameter $q$ so that (10) or (27) are satisfied because it is considered that the solution of the system (2) is not known. One way to estimate the parameter $q$ is the simulation of system (2) for known initial conditions. Therefore, the above mentioned theorems have more theoretical than practical significance.

\section{Modern (LMI) approach}

Finally, by using linear matrix inequalities, we give the sufficient conditions under which the system (2) will be regular, impulse free and finite time stable or attractive practically stable. LMI approach has been applied in order to get less conservative conditions. These stability conditions have a great practical impor- 
tance because they are based on standard numerical optimization methods.

Definition 5. Singular time delayed system (2) is finite-time stable with respect to $\{\alpha, \beta, T\}, \alpha<\beta$, if:

$$
\sup _{t \in[-\tau, 0]} \boldsymbol{\phi}^{T}(t) \boldsymbol{\phi}(t) \leq \alpha
$$

implies:

$\mathbf{x}^{T}(t) E^{T} E \mathbf{x}(t)<\beta, \forall t \in[0, T]$

Theorem 3. Singular time delayed system (2) is regular, impulse free and finite time stable with respect to $\{\alpha, \beta, T\}, \alpha<\beta$ if there exist a positive scalar $\wp$, nonsingular matrix $\mathbf{P}$ and two positive definite matrices $\Pi$ and $\mathbf{Q}$, such that the following conditions hold:

$$
\begin{aligned}
& P E=E^{T} P^{T} \geq 0 \\
& P E=E^{T} \Pi E \\
& \Xi=\left[\begin{array}{cc}
A_{0}^{T} P^{T}+P A_{0}+Q-\wp P E & P A_{1} \\
A_{1}^{T} P^{T} & -Q
\end{array}\right]<0
\end{aligned}
$$

and:

$$
\lambda_{\max }(P E)+\tau \lambda_{\max }(Q)<\frac{\beta}{\alpha} e^{-\wp T} \lambda_{\min }(\Pi)
$$

Proof. The proof of this theorem is divided into two parts. First, we deal with the regularity and impulsefree properties. Second, we treat the finite-time stability property.

First we show that the singular delay system (2) is regular and impulse-free. Using (48), it is easy to see that the following holds:

$$
A_{0}^{T} P^{T}+P A_{0}-\wp P E<0
$$

Now, we choose two nonsingular matrices $\mathbf{M}$ and $\mathbf{N}$ such that:

$$
\begin{aligned}
& \hat{E}=M E N=\left[\begin{array}{ll}
I_{r} & 0 \\
0 & 0
\end{array}\right], \quad \hat{A}_{0}=M A_{0} N=\left[\begin{array}{cc}
\hat{A}_{0}^{11} & \hat{A}_{0}^{12} \\
\hat{A}_{0}^{21} & \hat{A}_{0}^{22}
\end{array}\right], \\
& \hat{A}_{1}=M A_{1} N=\left[\begin{array}{ll}
\hat{A}_{1}^{11} & \hat{A}_{1}^{12} \\
\hat{A}_{1}^{21} & \hat{A}_{2}^{22}
\end{array}\right]
\end{aligned}
$$

Let:

$$
\hat{P}=N^{T} P M^{-1}=\left[\begin{array}{ll}
\hat{P}_{11} & \hat{P}_{12} \\
\hat{P}_{21} & \hat{P}_{22}
\end{array}\right]
$$

where the partitions of matrix blocks in Eq. (52) are compatible with those in Eq. (51). By Eqs. (46), (51) and (52) we have:

$$
\begin{aligned}
& P E=N^{-T}\left[\begin{array}{ll}
\hat{P}_{11} & 0 \\
\hat{P}_{21} & 0
\end{array}\right] N^{-1}, \\
& E^{T} P^{T}=N^{-T}\left[\begin{array}{cc}
\hat{P}_{11}^{T} & \hat{P}_{21}^{T} \\
0 & 0
\end{array}\right] N^{-1}
\end{aligned}
$$

From Eq. (53), it can be verified that:

$\hat{P}_{11}=\hat{P}_{11}^{T}, \quad \hat{P}_{21}=0$

By Eqs. (50), (51) and (52) it can be shown that:

$\hat{A}_{0}^{T} \hat{P}^{T}+\hat{P} \hat{A}_{0}-\wp \hat{P} \hat{E}<0$

Based on Eq. (54) we have:

$\left[\begin{array}{cc}\odot & \odot \\ \odot & \hat{A}_{0}^{22} \hat{P}_{22}^{T}+\hat{P}_{22} \hat{A}_{0}^{22}\end{array}\right]<0$

where the symbol " $\odot$ "stands for a matrix irrelevant to the following development. From Eq. (56) we deduce that:

$\hat{A}_{0}^{22 T} \hat{P}_{22}^{T}+\hat{P}_{22} \hat{A}_{0}^{22}<0$

i.e., $\hat{A}_{0}^{22} \neq 0$, because $\hat{P}_{22} \neq 0$. Therefore, by Definition 3 and Lemma 2, we conclude that the system (2) is regular and impulse-free.

Next, we show the stability. Let us consider the following Lyapunov-like function:

$V(\mathbf{x}(t))=\mathbf{x}^{T}(t) P E \mathbf{x}(t)+\int_{t-\tau}^{t} \mathbf{x}^{T}(\vartheta) Q \mathbf{x}(\vartheta) \mathrm{d} \vartheta$

Denote by $\dot{V}(\mathbf{x}(t))$ time derivative of $V(\mathbf{x}(t))$ along the trajectory of system (2), so one can obtain:

$$
\begin{aligned}
& \dot{V}(\mathbf{x}(t))=\dot{\mathbf{x}}^{T}(t) P E \mathbf{x}(t)+\mathbf{x}^{T}(t) P E \dot{\mathbf{x}}(t)+ \\
& +\frac{\mathrm{d}}{\mathrm{d} t} \int_{t-\tau}^{t} \mathbf{x}^{T}(\vartheta) Q \mathbf{x}(\vartheta) \mathrm{d} \vartheta \\
& =\mathbf{x}^{T}(t)\left(A_{0}^{T} P^{T}+P A_{0}\right) \mathbf{x}(t)+2 \mathbf{x}^{T}(t) P A_{1} \mathbf{x}(t-\tau)+ \\
& +\mathbf{x}^{T}(t) Q \mathbf{x}(t)-\mathbf{x}^{T}(t-\tau) Q \mathbf{x}(t-\tau)=\zeta^{T}(t) \Gamma \zeta^{T}(t)
\end{aligned}
$$

where:

$$
\begin{aligned}
& \zeta^{T}(t)=\left[\begin{array}{ll}
\mathbf{x}^{T}(t) & \mathbf{x}^{T}(t-\tau)
\end{array}\right], \\
& \Gamma=\left[\begin{array}{cc}
A_{0}^{T} P^{T}+P A_{0}+Q & P A_{1} \\
A_{1}^{T} P^{T} & -Q
\end{array}\right]
\end{aligned}
$$

From Eqs. (48) and (59), one can have: 
$\dot{V}(\mathbf{x}(t))=\zeta^{T}(t) \Gamma \zeta(t)=$

$=\zeta^{T}(t)\left(\Xi+\left[\begin{array}{cc}\wp P E & 0 \\ 0 & 0\end{array}\right]\right) \zeta(t)=$

$=\zeta^{T}(t) \Xi \zeta(t)+\zeta^{T}(t)\left[\begin{array}{cc}\wp P E & 0 \\ 0 & 0\end{array}\right] \zeta(t)$

$<\wp \mathbf{x}^{T}(t) P E \mathbf{x}<$

$\wp\left(\mathbf{x}^{T}(t) P E \mathbf{x}(t)+\wp \int_{t-\tau}^{t} \mathbf{x}^{T}(\vartheta) Q \mathbf{x}(\vartheta) d \vartheta\right)=$

$=\wp V(\mathbf{x}(t))$

Integrating (61) from 0 to $t \leq T$, follows:

$V(\mathbf{x}(t))<e^{\wp t} V(\mathbf{x}(0))$

Then:

$V(\mathbf{x}(0))=\mathbf{x}^{T}(0) P E \mathbf{x}(0)+\int_{-\tau}^{0} \mathbf{x}^{T}(\vartheta) Q \mathbf{x}(\vartheta) \mathrm{d} \vartheta$

Since:

$P E=E^{T} \Pi E$

From Eq. (63) and first condition of Definition 6, it follows:

$V(\mathbf{x}(0))=\mathbf{x}^{T}(0) P E \mathbf{x}(0)+$

$+\int_{-\tau}^{0} \mathbf{x}^{T}(\vartheta) Q \mathbf{x}(\vartheta) \mathrm{d} \vartheta$

$\leq \lambda_{\text {max }}(P E) \mathbf{x}^{T}(0) \mathbf{x}(0)+$

$+\lambda_{\max }(Q) \int_{-\tau}^{0} \boldsymbol{\phi}^{T}(\vartheta) \boldsymbol{\phi}(\vartheta) \mathrm{d} \vartheta$

$\leq \lambda_{\max }(P E) \alpha+\lambda_{\max }(Q) \alpha \int_{-\tau}^{0} \mathrm{~d} \vartheta \leq$

$\leq \alpha\left(\lambda_{\max }(P E)+\tau \lambda_{\max }(Q)\right)$

On the other hand, we have:

$V(\mathbf{x}(t))=\mathbf{x}^{\top}(t) P E \mathbf{x}(t)+\int_{t-\tau}^{t} \mathbf{x}^{T}(\vartheta) Q \mathbf{x}(\vartheta) \mathrm{d} \vartheta$

$>\mathbf{x}^{T}(t) P E \mathbf{x}(t)=\mathbf{x}^{T}(t) E^{T} \Pi E \mathbf{x}(t)>$

$>\lambda_{\text {min }}(\Pi) \mathbf{x}^{T}(t) E^{T} E \mathbf{x}(t)$

From Eq. (66) it is obvious that:

$\mathbf{x}^{T}(t) E^{T} E \mathbf{x}(t)<\frac{1}{\lambda_{\min }(\Pi)} V(\mathbf{x}(t))$
So, combining Eqs. (62), (65) and (67), leads to:

$\mathbf{x}^{T}(t) E^{T} E \mathbf{x}(t)<\frac{1}{\lambda_{\text {min }}(\Pi)} e^{\wp t} V(\mathbf{x}(0))<$

$<\alpha e^{\wp T} \frac{\lambda_{\text {max }}(P E)+\tau \lambda_{\text {max }}(Q)}{\lambda_{\text {min }}(\Pi)}$

Condition (49) and Inequality (68), imply:

$\mathbf{x}^{T}(t) E^{T} E \mathbf{x}(t)<\beta, \quad \forall t \in[0, T]$

This completes the proof.

Remark 4. It should be pointed out that the conditions in Theorem 4 are not classical LMIs conditions with respect to $\wp, \mathbf{P}, \boldsymbol{\Pi}$ and $\mathbf{Q}$.

Let:

$0<\lambda_{1}<\lambda_{\min }(\Pi), \lambda_{2}>\lambda_{\max }(P E)$,

$\lambda_{3}>\lambda_{\max }(Q)$

Then:

$\lambda_{1} l<\Pi, \quad \lambda_{2} l>P E, \quad \lambda_{3} I>Q$

$-\beta e^{-\alpha T} \lambda_{1}+\alpha \lambda_{2}+\alpha \tau \lambda_{3}<0$

From Relation (72) we have:

$-\beta e^{-\wp T} \lambda_{1}+\alpha \tau \lambda_{3}-\sqrt{\alpha} \lambda_{2}\left(-\lambda_{2}\right)^{-1} \sqrt{\alpha} \lambda_{2}<0$

Using Schur complement, we have:

$\left[\begin{array}{cc}-\beta e^{-\wp \top} \lambda_{1}+\alpha \tau \gamma_{3} & \sqrt{\alpha} \lambda_{2} \\ \sqrt{\alpha} \lambda_{2} & -\lambda_{2}\end{array}\right]<0$

$\left[\begin{array}{cc}-\beta e^{-\wp \top} \lambda_{1}+\alpha \tau \lambda_{3} & \sqrt{\alpha} \\ \sqrt{\alpha} & -\lambda_{2}\end{array}\right]-$

$-\left[\begin{array}{c}\sqrt{\alpha \tau} \lambda_{3} \\ 0\end{array}\right]\left(-\lambda_{3}\right)^{-1}\left[\begin{array}{ll}\sqrt{\alpha \tau} \lambda_{3} & 0\end{array}\right]<0$

$\left[\begin{array}{ccc}-\beta e^{-\wp \tau} \lambda_{1} & \sqrt{\alpha} \lambda_{2} & \sqrt{\alpha \tau} \lambda_{3} \\ * & -\lambda_{2} & 0 \\ * & * & -\lambda_{3}\end{array}\right]<0$

Once we fix $\wp$ for known $\alpha$ and $\beta$, the conditions (48) and (49) can be turned into LMIs based feasibility problem.

Corollary 1. Singular time delayed system (2) is regular, impulse free and finite time stable with respect to $\{\alpha, \beta, T\}, \alpha<\beta$, if for some fixed nonnegative scalar $\wp$ there exist positive scalars $\lambda_{1}, \lambda_{2}$ and $\lambda_{3}$, nonsingular matrix $\mathbf{P}$, positive definite matrices $\Pi$ and $\mathbf{Q}$, such that the following conditions hold: 


$$
\begin{aligned}
& P E=E^{T} P^{T} \geq 0 \\
& P E=E^{T} \Pi E \\
& {\left[\begin{array}{cc}
A_{0}^{T} P^{T}+P A_{0}+Q-\wp P E & P A_{1} \\
* & -Q
\end{array}\right]<0} \\
& \lambda_{1} I<\Pi, \quad \lambda_{2} I>P E, \quad \lambda_{3} I>Q \\
& {\left[\begin{array}{ccc}
-\beta e^{-\wp T} \lambda_{1} & \sqrt{\alpha} \lambda_{2} & \sqrt{\alpha \tau} \lambda_{3} \\
* & -\lambda_{2} & 0 \\
* & * & -\lambda_{3}
\end{array}\right]<0}
\end{aligned}
$$

Next, we give a definition of attractive practically stability and sufficient condition such that the system (2) is attractive practically stable.

Definition 6. Singular time delayed system (2) is attractive practically stable with respect to $\{\alpha, \beta, T\}$, $\alpha<\beta$ if:

$$
\sup _{t \in[-\tau, 0]} \boldsymbol{\phi}^{T}(t) \boldsymbol{\phi}(t) \leq \alpha
$$

implies:

$\mathbf{x}^{T}(t) E^{T} E \mathbf{x}(t)<\beta, \quad \forall t \in[0, T]$

with the following property:

$\lim _{t \rightarrow \infty} x^{T}(t) x(t) \rightarrow 0$

Theorem 4. Singular time delayed system (2) is regular, impulse free and attractive practically stable with respect to $\{\alpha, \beta, T\}, \alpha<\beta$, if there exist positive definite matrices $\mathbf{X}$ and $\mathbf{Y}$ such that the following conditions hold:

$$
X E=E^{T} X^{T} \geq 0
$$

$\left[\begin{array}{cc}A_{0}^{T} X^{T}+X A_{0}+Y & X A_{1} \\ * & -Y\end{array}\right]<0$

and nonnegative scalar $\wp$, positive scalars $\lambda_{1}, \lambda_{2}$ and $\lambda_{3}$, nonsingular matrix $\mathbf{P}$, positive definite matrices $\Pi$ and $\mathbf{Q}$, such that the following conditions hold:

$$
\begin{aligned}
& P E=E^{T} P^{T} \geq 0 \\
& P E=E^{T} \Pi E \\
& {\left[\begin{array}{cc}
A_{0}^{T} P^{T}+P A_{0}+Q-\wp P E & P A_{1} \\
* & -Q
\end{array}\right]<0} \\
& \lambda_{1} I<\Pi, \quad \lambda_{2} I>P E, \quad \lambda_{3} I>Q
\end{aligned}
$$

$$
\left[\begin{array}{ccc}
-\beta e^{-\wp T} \lambda_{1} & \sqrt{\alpha} \lambda_{2} & \sqrt{\alpha \tau} \lambda_{3} \\
* & -\lambda_{2} & 0 \\
* & * & -\lambda_{3}
\end{array}\right]<0
$$

Proof. The regularity and impulse free properties are proved in the previous theorem.

Based on Corollary 1, the first and second conditions of Definition 6 follow directly from Eqs. (87)-(91). Further, if conditions (77) and (79) are satisfied with $\wp=0$, then system (2) is asymptotically stable which implies (84). Since conditions (85) and (86) are equivalent to conditions (77) and (79) with $\wp=0$, it follows that the third condition of Definition 6 is also satisfied.

This completes the proof.

Remark 5. According to our knowledge, there are no results available yet on finite-time stability and attractive practical stability in the sense of Definition 5 and 6 for a class of linear continuous time-delay systems that use linear matrix inequality. Therefore, we cannot to compare our results with existing ones.

\section{NUMERICAL EXAMPLES}

The effectiveness of the results presented in the previous section is now shown by means of numerical examples. Based on Remark 3, we give solutions of two problems of the finite-time and attractive practical stability using Theorem 3 (Corollary 1 ) and Theorem 4.

Example 1. Consider following unstable singular continuous time-delay system:

$E \dot{x}(t)=A_{0} x(t)+A_{1} x(t-\tau)$

$E=\left[\begin{array}{lll}1 & 0 & 0 \\ 0 & 1 & 0 \\ 0 & 0 & 0\end{array}\right], \quad A_{0}=\left[\begin{array}{ccc}-2 & 1 & 0 \\ 0 & -2 & 0 \\ -1 & 0 & -2\end{array}\right]$,

$A_{1}=\left[\begin{array}{ccc}0.5 & 1 & 0 \\ 1 & 0.5 & 1 \\ 1 & 1 & 0\end{array}\right], \quad \tau=1$

One should investigate finite-time stability of the system (92) with respect to $\alpha=3, \beta=100$ and $T=5$. Based on Corollary 1 , for fixed $\gamma=0.38$, we can obtain the following feasible solutions:

$$
\begin{aligned}
& \mathbf{P}=\left[\begin{array}{ccc}
5.7484 & -1.1447 & -1.3063 \\
-1.1447 & 9.6663 & 2.8294 \\
0 & 0 & 5.3187
\end{array}\right], \\
& \mathbf{Q}=\left[\begin{array}{lll}
10.927 & 1.7094 & 1.9388 \\
1.7094 & 10.738 & 1.4311 \\
1.9388 & 1.4311 & 8.9738
\end{array}\right],
\end{aligned}
$$




$$
\begin{aligned}
& \Pi=\left[\begin{array}{ccc}
5.7484 & -1.1447 & 0 \\
-1.1447 & 9.6663 & 0 \\
0 & 0 & 1.5554
\end{array}\right], \quad \lambda_{1}=5.2451, \\
& \lambda_{2}=10.786, \lambda_{3}=14.575
\end{aligned}
$$

Therefore, the system (92) is regular, impulse free and finite-time stable with respect to $(3,100,5)$.

Example 2. Consider following singular continuous time-delay system:

$$
\begin{aligned}
& E \dot{x}(t)=A x(t)+A_{d} x(t-\tau) \\
& E=\left[\begin{array}{lll}
1 & 0 & 0 \\
0 & 1 & 0 \\
0 & 0 & 0
\end{array}\right], \quad A=\left[\begin{array}{ccc}
-1 & 1 & 5 \\
0 & -2 & 0 \\
-1 & 0 & -1
\end{array}\right], \\
& A_{d}=\left[\begin{array}{ccc}
-0.2 & 0.1 & 0.1 \\
0 & -0.1 & 0 \\
0 & 0 & -0.2
\end{array}\right], \quad \tau=1
\end{aligned}
$$

Solving the LMI (79), for $\wp=0$ we get the following feasible solutions:

$$
\begin{aligned}
& \mathbf{X}=\left[\begin{array}{ccc}
19.727 & 2.6273 & 37.521 \\
2.6273 & 31.397 & 12.165 \\
0 & 0 & 56.386
\end{array}\right]>0, \\
& \mathbf{Y}=\left[\begin{array}{ccc}
56.737 & 0.1068 & -1.5756 \\
0.1068 & 58.682 & -0.3238 \\
-1.5756 & -0.3238 & 56.162
\end{array}\right]>0
\end{aligned}
$$

Thus, the system is asymptotically stable which implies $\lim x^{T}(t) x(t) \rightarrow 0$ (attractive propriety).

Let us check the conditions (87)-(91) with respect $\alpha$ $=3, \beta=3.3$ and $T=200$ for fixed $\wp=1 \times 10^{-4}$. The following feasible solutions are obtained:

$$
\begin{aligned}
& \mathbf{P}=\left[\begin{array}{ccc}
9.5757 \times 10^{2} & -4.2053 \times 10^{-3} & 7.4462 \times 10^{2} \\
-4.2053 \times 10^{-3} & 9.5765 \times 10^{2} & 9.1516 \times 10^{2} \\
0 & 0 & 2.6480 \times 10^{3}
\end{array}\right], \\
& \mathbf{Q}=\left[\begin{array}{ccc}
49.107 & -2.3894 & 4.6023 \\
-2.3894 & 48.648 & -1.4973 \\
4.6023 & -1.4973 & 70.497
\end{array}\right], \\
& \Pi=\left[\begin{array}{ccc}
9.5757 \times 10^{2} & -4.2053 \times 10^{-3} & 0 \\
-4.2053 \times 10^{-3} & 9.5765 \times 10^{2} & 0 \\
0 & 0 & 1.6111 \times 10^{3}
\end{array}\right]
\end{aligned}
$$

$\lambda_{1}=956.59, \lambda_{2}=958.71, \lambda_{3}=72.192$
Therefore, the system (93) is regular, impulse free and attractive and practically stable with respect to $(3,3.3,200)$.

\section{CONCLUSION}

Generally, this paper extends some of the basic results in the area of the non-Lyapunov stability to the particular class of linear singular time-delay systems. The finite-time and attractive practical stability problems of linear singular time-delay systems are studied. Using classical and LMI approaches novel sufficient conditions for both finite-time stability and attractive practical stability are presented. The obtained LMI conditions can be checked using the standard numerical optimization methods. Finally, two numerical examples are given to show the effectiveness of the proposed approaches.

\section{Acknowledgment}

This work has been supported by the Ministry of Education, Science and Technological Development of the Republic of Serbia under the Project ON 174001.

\section{REFERENCES}

[1] S.L. Campbell, Singular Systems of Differential Equations, Pitman, London, 1980.

[2] P.C. Müller, Stability of Linear Mechanical Systems with Holonomic Constraints, Appl. Mech. Rev. 46 (1993) 60-164 .

[3] C.C. Pantelides, D. Gridsis, K.R. Morison, R.W.H. Sargent, The mathematical modeling of transient systems using differential-algebraic equations, Comp. Chem. Eng. 12 (1988) 449-454.

[4] A. Kumar, P. Daoutidis, Control of nonlinear differential algebraic equation systems: an overview, Proc. NATO Advanced Study Institute on Nonlinear Model Based Process Control, Antalya, Turkey, August 10-20, 1997, pp. 311-344.

[5] A. Rehm, F. Allgower, H-Infinity Control of Descriptor Systems: An application from binary distillation control, in Proc. of 7 International Symposium on Advanced Control of Chemical Processes, Hong Kong, 2004.

[6] S. Xu, P.V. Dooren, R. Stefan, J. Lam, Robust stability and stabilization for singular systems with state delay and parameter uncertainty, IEEE Trans. Automat. Contr. 47 (2002) 1122-1128.

[7] S. Xu, J. Lam, C. Yang, $H_{\infty}$ control for uncertain singular systems with state delay, Int. J. Robust Nonlin. Contr. 13 (2003) 1213-1223.

[8] E. Fridman, Stability of linear descriptor systems with delay: a Lyapunov-based approach, J. Math. Anal. Appl. 273 (2002) 24-44.

[9] D. Yue, Q.-L. Han, Delay-dependent robust $\mathrm{H}_{\infty}$ controller design for uncertain descriptor systems with time-varying discrete and distributed delays, IEE P-Contr. Theor. App. 152 (2005) 628-638. 
[10] S. Zhu, C. Zhang, Z. Cheng, J. Feng, Delay-dependent robust stability criteria for two classes of uncertain singular time-delay systems, IEEE Trans. Automat. Contr. 52 (2007) 880-885.

[11] S. Xu, J. Lam, Y. Zou, An improved characterization of bounded realness for singular delay systems and its applications, Int. J. Robust Nonlin. Contr. 18 (2008) 263$-277$.

[12] L. Dai, Singular Control Systems, Springer, Berlin, 1981.

[13] D.Lj. Debeljkovic, M.P. Lazarevic, Dj. Koruga, S. Tomasevic, Finite time stability of singular systems operating under perturbing forces: Matrix measure approach, in Proc. of AMSE Conference, Melbourne, Australia, 1997, pp. 447-450.

[14] N.A. Kablar, D.Lj. Debeljkovic, Non-Lyapunov stability of linear singular systems: Matrix measure approach, in Proc. of Mathematical Theory of Networks and Systems, Padova, Italy, 1998.

[15] N.A. Kablar, D. Lj. Debeljkovic, Non-Lyapunov stability of linear singular systems: Matrix measure approach, in Proc. of $5^{\text {th }}$ IFAC Symposium on Low Cost Automation, Shenyang, China, 1998, pp. 16-20.

[16] N.A. Kablar, D.Lj. Debeljkovic, Finite time stability of time varying singular systems, in Proc. of IEEE Decision and Control, USA, 1998, pp. 3831-3836.

[17] D.Lj. Debeljkovic, N.A. Kablar, On necessary and sufficient conditions of linear singular systems stability operating on finite time interval, in Proc. of XII CBA, Uberlandia, Brazil, 1998, Vol. IV, pp. 1241-1246.
[18] N.A. Kablar, D.Lj. Debeljkovic, Finite time instability of time varying linear singular systems, in Proc. of IEEE ACC 99, San Diego, CA, 1999, pp. 1796-1800.

[19] D.Lj. Debeljkovic, N.A. Kablar, Finite time stability of linear singular systems: Bellman-Gronwall approach, in Proc. of IEEE ACC 99, San Diego, USA, 1999, pp. 1803$-1806$.

[20] C. Yangy, Y.Q.Zhang, Y.Linz, L. Zhouy, Practical stability of closed-loop descriptor systems, Int. J. Syst. Sci. 37 (2006) 1059-1067.

[21] F. Jun-E, W. Zhen, S. Jia-Bing, Finite-time control of linear singular systems subject to parametric uncertain and disturbances, Acta Autom. Sin. 31 (2005) 634-637.

[22] C.Y. Yang, X. Jing, Q.L. Zhang, L.N. Zhou, Practical stability analysis and synthesis of linear descriptor systems with disturbances, Int. J. Automot. Comput. 5 (2008) 138-144.

[23] C. Yang, Q. Zhang, L. Zhou, Practical stability of descriptor systems with time delays in terms of two measurements, J. Franklin Inst. 343 (2006) 635-646.

[24] M. Su, S. Wang, X. Zhang, Finite-Time Stabilization for Singular Linear Time-delay Systems with Time-varying Exogenous Disturbance, Adv. Mater. Res. 490-495 (2012) 2459-2463.

[25] D.H. Owens, D.Lj. Debeljkovic, Consistency and lyapunov stability of linear descriptor systems: a Geometric analysis, IMA J. Math. Control. Inf. 2 (1985) 139-151.

[26] J. K. Hale, Theory of Functional Differential Equations, Springer-Verlag, New York, 1977.

\section{IZVOD}

\section{NE-LAPUNOVSKA STABILNOST SINGULARNIH SISTEMA SA ČISTIM VREMENSKIM KAŠNJENJEM: KLASIČAN I SAVREMEN PRISTUP}

Dragutin Lj. Debeljković ${ }^{1}$, Sreten B. Stojanović ${ }^{2}$, Marko S. Aleksendrić ${ }^{1}$

${ }^{1}$ Univerzitet u Beogradu, Mašinski fakultet, Beograd, Srbija

${ }^{2}$ Univerzitet u Nišu, Tehnološki fakultet, Leskovac, Srbija

(Naučni rad)

U ovom radu izvedeni su dovoljni uslovi kako praktične tako i stabilnosti na konačnom vremenskom intervalu linearnih singularnih sistema sa čistim vremenskim kašnjenjem, koji se u matematičkom smislu mogu opisati sledećim modelom: $E \dot{x}(t)=A_{0} x(t)+A_{1} x(t-\tau)$. Razmatrajući koncept stabilnosti na konačnom vremenskom intervalu, izvedeni su novi, dovoljni uslovi stabilnosti, koji ne uzimaju i koji uzimaju u obzir iznos čisto vremenskog kašnjenja, koristeći prilaz koji se zasniva na korišćenju kvazi Ljapunovljevih funkcija i njihovih osobina na podprostoru konzistentnih početnih uslova. Ove funkcije ne moraju da budu pozitivno određene $u$ celom prostoru stanja, kao što i njihovi izvodi duž trajektorija sistema ne moraju da budu negativno određene funkcije. Kada je razmatran koncept praktične stabilnosti, prethodno pomenuti prilaz kombinovan je sa klasičnim Ljapunovskom tehnikom kako bi se obezbedila atraktivna (privlačna) praktična stabilnost razmatranog dinamičkog ponašanja sistema. Štaviše, prilaz sa stanovišta LMI (eng. linear matrix inequality) metoda je takođe primenjen sa ciljem da se oslabe neki od ograničavajućih uslova iz prethodnih rezultata.
Ključne reči: Singularni sistem • Vremensko kašnjenje • Stabilnost na konačnom vremenskom intervalu • Atraktivna praktična stabilnost • Linearna matrična nejednakost 